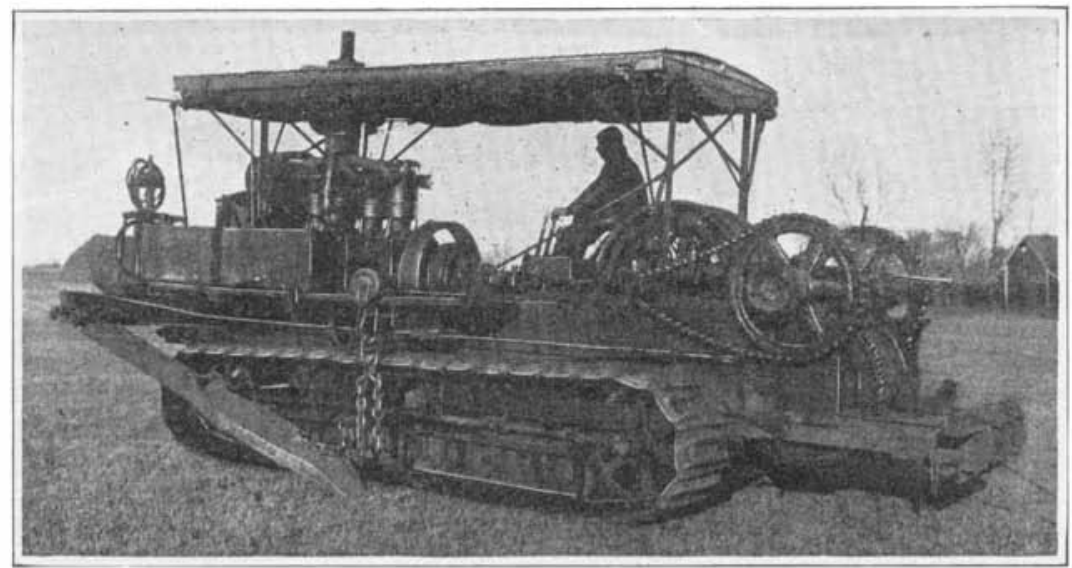

A gasoline tractor fitted with a powerful winch for hauling the plow.

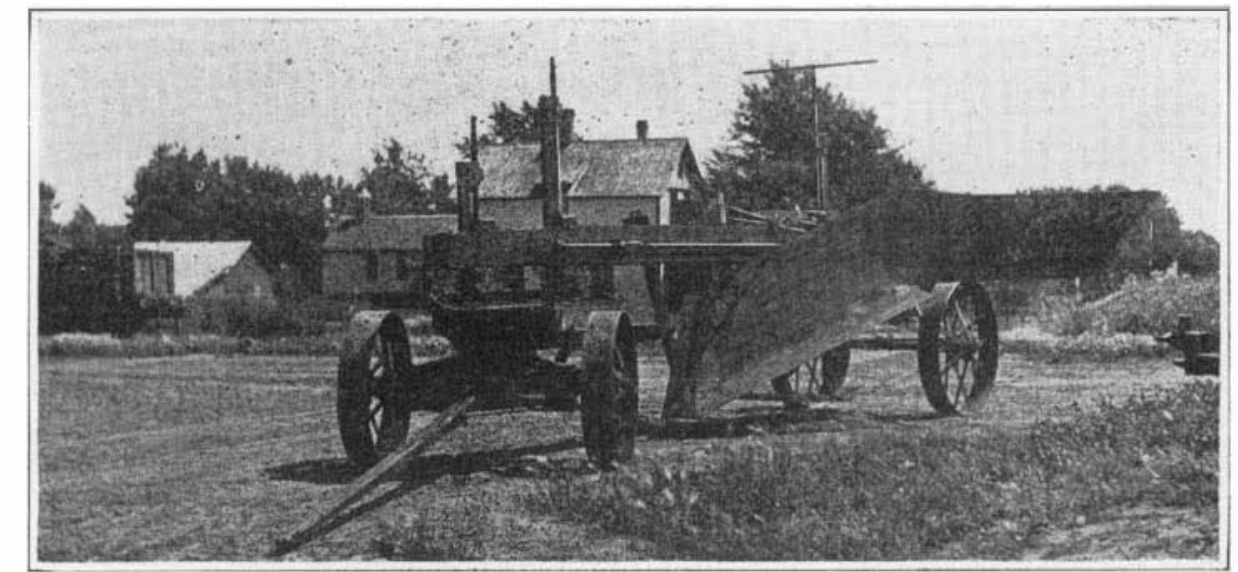

A big ditching plow mounted on wheels ready for transportation.

\section{Wood Flour}

By Frederick W. Kressmann, Chemist in Forest Pro ducts, Forest Products Laboratory, Madison, Wis.

Woov flour is ground or milled wood that has been screened so as to remove coarse particles and also to give particles having some uniformity in size. Wood
flour is usually sold as 40, 60, or 80 mesh,* although one large foreign purchaser has the following specification for dynamite flour:

20 per cent must pass through an 80 mesh screen.

50 per cent must pass through a 60 mesh screen.

100 per cent must pass through a 50 mesh screen.

The different properties of a good wood flour are: 1st, it must be white; 2nd, it must be light and fluffy 3rd, it must be absorptive.

All industries in which wood flour is used (and these will be considered in greater detail later), require a white or very light cream-colored flour, although abwhite or very light cream-colored flour, although ab-
sorptive qualities are demanded in a large degree only in dynamite flours. Color and weight considerations, therefore, limit the species of wood which may be used to the white, light, non-resinous conifers and to the white, broad-leaved woods like aspen and poplar. Suruce, white pine and poplar are the species most often used. The wood must be barked before grinding and used. The wood must be barked before grinding and round wood, slabs
bark may be used.

bark may be used.
The grinding of the wood is performed in two distinct types of apparatus, either stone mills or steel burr roller mills. In Europe, particularly Scandinavia, where a great deal of wood flour is made, the stone mills seem to be used exclusively, and most of the early plants in this country use this type of mill. The stones are from 40 to $; 0$ inches in diameter and only the lower stone is driven, the upper one being stationary. The mills are driven with water power turbines, since flour produced with other sources of power cannot compete with Norwegian flour ground by water power.

The wood after barking is flrst reduced to chips by means of the usual type of chipper or hog. These chips along with a certain proportion of the screenings are fed to the mills, which are completely enclosed (with the exception of an opening at the top) with an iron or steel cover. Sufficient steam or water is added to prevent fring, and also to keep down the dust. The flne stuff from the mill is then drawn or blown through iron pipes or sheet metal ducts to the screening apparatus, which may be of several types, and which may ratus, which may be of several types, and which may
be either bronze wire or silk bolting cloth, for both are be either bronze wire or silk bolting cloth, for both are
used. After screening the flour is packed either in comused. After screening the flour is packed either in com-
pressed bales (the imported material comes in this way) or else is sacked with automatic sacking and weighing machinery.

Mills of the above type require from 45 to 50 horsepower per 24 hours per ton (from 1,200 to as high as 1,500 horse-power hours per ton) of flour produced, the power requirement being about the same as in the production of mechanical ground wood pulp.

Another type of mill was developed on the Paciflc Coast about 25 years ago, and was designed especially to handle sawdust as a raw material. This grinder consists of a number of pairs of corrugated chilled steel rolls which turn towards each other. One of the rolls rotates three times as fast as the other, thereby actually cutting the sawdust which comes between them. The slower roll has its corrugations arranged so that they form pockets to hold the dust while the of rolls, the corrugations being progressively finer on each stand.

The sawdust is screened before reaching the first rolls so as to remove slivers, small blocks, etc. It is then passed over a strong electric magnet to pick out any -Screens of bronze wire having 40,60 or 80 meshes per linear inch. liarticle of iron or steel present, and is also screened through bolting cloth between each pair of rolls to remove material of suitable flneness. The production of wood flour from sawdust in this type of mill requires only from 20 to 25 per cent of the power required with the stone mills.

Before the war Norwegian wood flour was delivered at our Atlantic ports for from $\$ 12.50$ to $\$ 15.00$ per ton and domestic material sold in competition therewith. The domestic production is largely controlled by one concern, although mills are scattered all over the country from Maine to California wherever the combination of proper wood and water power is available.

\section{USES.}

The principal uses for wood flour are in the manufacture of dynamite, linoleum, artificial plastics and flooring, and as an inert absorbent in many industries. DYNAMITE.

Dynamite consists essentially of nitroglycerine absorbed in some porous material. For this purpose woo flour, wheat flour mill refuse and infuserial earth (Kieselguhr) are the principal materials used, and wood flour is the one commonly used to-day. In addition, a certain amount of oxidizing material, either sodium or potassium nitrate with traces of calcium carbonate, magnesium carbonate, or zinc oxide are used. The latter materials are added to neutralize any free acid that may be formed by the decomposition of the nitroglycerine in long stornge.

The composition of typical dynamites is as follows:

\section{Noisture}

Nitroglycerine

Sodium or pota
Wood flour

Wood flour --.-
Calcium carbonat

$\begin{array}{rr} & 1.4 \\ 40 & 60.6 \\ 44 & 18.6 \\ 15 & 18.2 \\ 1 & 1.2\end{array}$

A dynamite flour must be both white and highly ab sorptive. Since dynamite darkens with age a lightcolored stick is indicative of fresh stock, and trad demands, therefore, require the use of a white flour. For this reason it would be practically imposible to introduce the use of a wood flour produced from any colored woods. A good flour should be capable of making a 60 or 70 per cent dynamite ( 60 or 70 per cent of the total weight being nitroglycerine), without permitting leakage or exudation of nitroglycerine. ${ }^{2}$ It is
possible to improve the absorptive qualities and powe possible to improve the absorptive qualities and power
of a flour by mixing it with water, boiling it actively or a short time and then drying, although this process, of course, increases the cost of production appreciably. For dynamite purposes, therefore, wood flour must be as white as possible, it must be absorptive and must be of the proper weight, not only because the size of stick and number of sticks per box is standard, but also because too much flour cannot be used because it would surely disturb the carbon and oxygen balance in the explosive.

In 1900 over $85,846,000$ pounds of dynamite were produce in the United States, containing over 9,934,000 pounds of wood flour. In 1909 the production of dynamite increased to about $195,156,000$ pounds, althoug the amount of wood flour used in this dynamite wa not stated. The proportion of wood flour used in dynamite in 1909 was probably greater than in 1900 becaus of a tendency to produce dynamites of a greater strength and the gradual replacement of other absorbents with wood flour. The 1909 consumption of wood flour for dynamite was probably around $20,000,000$ pounds. Since 1909 the production of dynamite has no doubt continued 1909 the production of dynamite has
to expand and develop as before.

'Bureau of Mines, Bulletin No. 51, "The Analysis of Black Powder Dynamite," by W. O. Snelling and C. G. Storm.
2For pressure and centrifugal tests see page $\mathbf{9}$, Bulletir

${ }^{2}$ For pressure and
I.INOLEUM.

In the manufacture of linoleum, wood flour is used exclusively in the production of goods belonging to the inlaid class, either "granulated inlaid" or "straight line." Cork linoleum is always dark, either the natural brown, or dark red or green. Patterns are printed on cork linoleum, but the pattern soon wears off leaving the dark base. For the production of inlaid goods, in which the pattern goes clear through the plece to the burlap backing, a white base is naturally necessary, not only to furnish a white background where desired but also to permit of dyeing to any color. For this reason a flour as white as possible is desirable.

Linoleum consists of wood flour or cork flour mixed with a cementing material which is spread out on burlap and rolled or pressed hydraulically thereon. The cement consists of oxidized linseed oil melted with rosin and Kauri gum. The cement is the expensive constituent, it being worth from $\$ 125.00$ to $\$ 175.00$ per ton, depending on the price of linseed oil. Naturally the lightest flour will produce the largest volume of goods, since the raw materials of linoleum are purchased on a weight basis and sold on a volume basis. The weight per cubic feet is, therefore, along with the color, of prime consideration to the linoleum manufacturer.

The following table shows the comparative weights per cubic foot of cork and wond flours of different sizes :

28 mesh cork
56 mesh cork

Another manufacturer reports as follows:
26 mesh corl
4 to $4.5 \mathrm{cu}$. $\mathrm{ft}$.
60 to 80 mesh wood, imported
$4.8 \mathrm{cu} . \mathrm{ft}$.

The difference in the above figures is due chiefly to the method of measuring and the alnount of tamping in the measure, but in either case the wood flour weighs about 50 per cent to 100 per cent more than the corls. Cork waste before the war was worth about $\$ 35.00$ per ton and it costs about $\$ 5.00$ per ton to grind it with power at $11 / 2$ cents per kilowatt. Practically all cork flour used in this country is ground here either from domestic waste or waste from Spanish cork mills. Cork flour is, therefore, worth about three times as much as wood flour; but since they both require equal amounts by weight of cement, and since the latter is the expensive item, and also because the volume of goods produced from cork is so much greater than that from wood, the cork linoleum is cheaper for goods of equal thickness than wood flour linoleum. Cork linoleum is also cheaper to manufacture than wood linoleum because it is simply rolled between calender rolls, whereas the production of inlaid linoleum requires a considerable amount of handwork in the production of granulated inlaid and also a tremendous expense for dies in the production of "straight line." The seasoning time for cork is also less than wood flour linoleum of equal thickness. Cork linoleum is slightly more elastic than wood flour linoleum, although wearing qualities are about the same.

MINOR USES.

For composition flooring, plastics, oatmeal paper, ete., the principal requirement is light color, although in some cases certain species are necessary, as in the production of artiflcial bates for tanneries. The latter consists of a mixture of wood flour, ammonium chloride and certain animal extracts which are absorbed by the wood flour. Here again the trade demands a lightcolored product, and it has been found that flour from broad-leaved woods, like poplar, will cause a discoloration on storage, so that only flour from spruce or white plne may be used. 